\title{
THE UTILIZATION OF MILK-FAT BY AN ATROPHIC INFANT *
}

\author{
A. H. WENTWORTH, M.D. \\ BOSTON
}

This paper furnishes a comparison of the results obtained from three observations made on an atrophic infant in which the absorption of fat was determined. Each observation lasted for three days, during. which time the fat in the food and feces was determined.

For twelve days immediately preceding the first observation the infant was fed exclusively on human milk and the first observation succeeded this preliminary period without interruption. There was an interval of four days between the first and second observations and an interval of three dars between the second and third observations.

During the first observation the infant was given 840 c.c. of breastmilk daily. During the second observation he was given 840 c.c. daily of a mixture of cows' milk containing approximately 3 per cent. of fat, 6 per cent. of milk-sugar and 1 per cent. of protein.

During the third observation the infant was given 840 c.c. daily of a mixture of cows' milk prepared with rennet, in which the percentages of fat, sugar and protein were approximately the same as during the second observation.

In the interval between the first and second observations the infant was fed on breast-milk. The reason for this will be referred to later. In the interral between the second and third observations he was given the same preparation of cows' milk treated with rennet that he received during the third observation.

Carmin was given at the beginning and end of each observation.

PREPARATION OF THE FOOD

'The fat in the eream that was used to prepare the cows'-milk mixtures was determined each day by the Babcock method, and the milk mixtures were prepared to contain approximately the desired percentage of fat. In each feeding-bottle 105 c.c. of the mixture were put, and, to avoid any chance of accidental spilling, the rubber nipples were fastened to the feeding bottles by strips of adhesive plaster. The infant received eight

* From the Biochemical Laboratory of the Harvard Medical School.

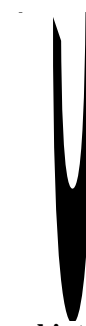


feedings in twenty-four hours. After each feeding the bottles were set aside until the next day, and then they were carefully rinsed and the fat in the rinsings was ultimately determined and the amount deducted from the total fat ingested. The amount of fat thus left was between 2.5 and 3 per cent. of the total quantity ingested.

In the third observation rennet was added to the milk to produce a finer subdivision of the fat. It appeared probable that, when cows' milk coagulated in more or less large and tough curds in the stomach, some of the fat which was enmeshed in these curds escaped digestion. If, therefore, the casein was coagulated before ingestion and was then passed through a fine-meshed sieve it was hoped that, though the fat would still remain mechanically bound to the casein, it would nevertheless be more finely subdivided and in this way its digestion would be favored.

In order to test this hypothesis, a mixture of cows' milk containing approximately 3 per cent. of fat was prepared and treated with rennet. On attempting to rub the coagulum through a sieve it was found that a considerable portion did not pass through and when this portion was squeezed between the fingers it was found to contain fine, hard particles. Professor Folin suggested that I add the rennet to the cream and prepare the mixture afterward.

The required number of ounces of cream to give 3 per cent. fat in the mixture was treated with rennet and it was then found that the entire coagulum could be pressed through the sieve and that, when squeezed between the fingers, it smoothed out without leaving hard particles. When mixed with the other ingredients of the milk mixture it settled to the bottom of the nursing-bottle, but with a somewhat larger aperture in the nipple, and by shaking the bottle occasionally during the feeding, very little remained behind. The amount of fat not ingested did not exceed that of the other periods.

\section{COLLECTION OF FECES}

The urine was not required for these observations, and a simple and effectual device was employed to prevent the admixture of urine and feces. The penis was put through a small opening in a sheet of rubber dam. The edge of the opening was fastened to the penis by a narrow strip of adhesive plaster. The rubber dam was pinned to the mattress on either side. Napkins were placed under and over the penis to absorb the urine.

In previous metabolism observations I made use of a Bradford frame to collect the feces and urine. This time I used a mattress such as the infant 
was accustomed to. A suitable opening was made in the mattress, and the edges and several inches of mattress adjoining the edge on both sides were covered with rubber sheeting. A wire tray was fastened to the bed beneath the hole and close to the mattress. The wire tray held an oblong baking-tin a little smaller than the tray in which the feces were collected. These pans could be removed and replaced merely by sliding them in and out of the wire tray. During the observations the infant necessarily required more attention than usual and he was invariably cheerful when awake and slept normally.

\section{METHOD OF ANALYSIS}

During the three metabolism periods the fat in the food was determined each day by the Soxhlet method. Duplicate analyses were always made. Following the method of Black for the determination of oxybutyric acid ${ }^{1}$ in the urine, plaster of Paris was added to 20 c.c. of the milk with constant stirring until the desired consistency was reached. It was then kept in the ice-chest until it could be analyzed. It crumbled readily when dry and afforded a very simple and convenient method for determining the fat in milk.

It was impossible by this method to make analyses of the rennet preparation agree, because of the unequal distribution of the fat. The difficulty was overcome by accurately weighing and measuring a considerable quantity of the rennet milk mixture, evaporating this to dryness, reweighing the dried residue and then extracting the fat from weighed portions. The total fat was calculated from this result. In this way very close controls were obtained. Sulphuric ether was used in the food analyses.

The fat was determined in the feces by a method recently devised by Professor Folin. ${ }^{2}$ Some of the analyses of fat in the feces made last year by an older method did not check and so I discarded them all and applied to Professor Folin for a more accurate method. Thus far the method has not been tested in substances other than feces and here it appears to give very accurate results. Briefly described, Folin's method is as follows:

The fat is extracted with acid-ether, prepared by passing dry hydrochloric acid gas into anhydrous ether (the degree of acidity is controlled by titration). The extract is evaporated to dryness and allowed to stand over night under petroleum ether. The petroleum ether solution is carefully filtered, dried at a temperature under $100 \mathrm{C}$. and weighed as total fat. The fat is then dissolved in benzol, heated to boiling and titrated, while hot, against a standard solution

1. Black, O. F.: Jour. Biol. Chem., 1908, v.

2. Folin: Jour. Biol. Chem., June, 1910. 
of metallic sodium in absolute alcohol, using phenolphthalein as indicator. The end point is very sharply defined. When a large quantity of fatty acid is present it is advisable to continue the heat during titration. In this way the soap, which is formed, is kept in solution and permits of a sharp end point. If it is desired to estimate the fat which is present in the form of soaps, then anhydrous sulphuric ether is used for a first extraction with subsequent treatment with petroleum ether, etc, as described above, and this is followed by a second extraction with acid ether, etc., thus making two procedures which are identical, including the titration, except that two solvents are used. The first extraction removes the neutral fat and fatty acids; the second extraction removes the soaps which have been converted into fatty acids.

Table: 1.-Determinatiox of Fat ix Feces

1st Period, March 4 to $6 .-$

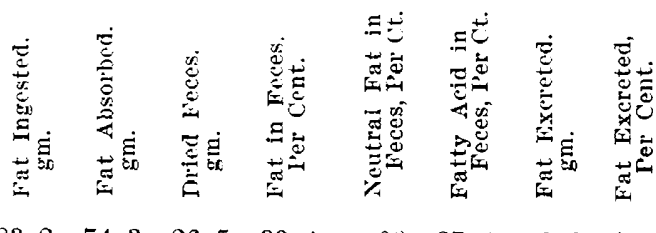

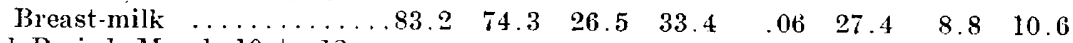

2d Period, March 10 to 12.-

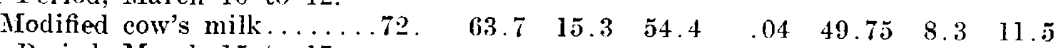

3d Period, March 15 to $1 \bar{i} \cdot-\overline{-}$
Modified cow's mill with

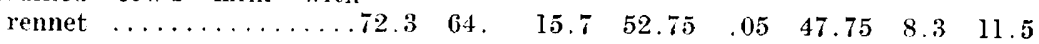

\section{GEXERIL CONSIDERATION}

Before discussing the results of this observation it is necessary to consider certain points in connection with the feeding which bear directly on the results.

In the interval between the breast-milk and the first cows'-milk observation the baby was fed on breast-milk. I intended to have the infant fed on the same mixture of cows' milk that was given during the second olservation, but concluded not to do so, because he previously had shown a lack of tolerance for cows' milk, and I wished to test his absorptive powers for cows' milk under the most favorable conditions. A comparison of the second and third observations shows that the results were almost identical, so that the interval of breast-milk feeding did not appear to exert any marked influence on the second observation. I did not wish to. test the tolerance of the infant for cows'-milk fat, but, on the other hand, I desired him to ingest, if possible, an amount of fat compatible with a gain in weight. In addition to this, it was desirable for purposes of complarison that approximately the same quantity of fat should be ingested in each observation, and it was improbable that the breast-milk would contain much less than 3 per cent. of fat. 
At the hour selected to begin the first observation a Babcock test of the breast-milk showed 5.4 per cent. of fat. As the supply of breast-milk was limited I had the alternative of postponing the observations, with a very good chance that something else would occur to complicate matters, or of using this milk for the first twenty-four hours and securing milk from another wet-nurse for the remaining forty-eight hours. Under the circumstances it seemed wiser not to postpone the observation.

At the end of the first twenty-four hours the infant was not so hungry as usual and left some of the milk. On the next day the milk was obtained from another wet-nurse and contained 2.5 per cent. of fat. The baby's appetite returned and he showed no further signs of disturbance. The excessive quantity of fat taken the first day may have influenced the subsequent absorption of fat. The weight of dried feces during the breastmilk period very much exceeded that of either of the other two periods. There is always an unknown and unavoidable error in the segregation of feces, but the difference between these periods appears to me to be larger than can be accounted for on this ground.

\section{CONSIDERATION OF RESULTS}

The dried feces from the breast-milk period contained 33.4 per cent. of fat; from the first cows'-milk period 54.4 per cent. and from the second cows'-milk period 52.75 per cent. This difference between the breast and cows'-milk periods is offset to a great extent when the total percentage of excreted fat is estimated. If we assume that the fat in the feces represents fat that las been ingested, then 10.6 per cent. of the ingested fat was excreted in the feces during the breast-milk period against 11.5 per cent. during each of the cows'-milk periods. I have little doubt that the absorption of fat during the breast-milk period was disturbed by the excessive quantity of fat ingested the first day, and that these percentages do not afford an accurate basis for comparison of the three periods. If we consider the actual quantity of fat ingested and absorbed in each of the three periods an entirely different result is obtained. During the breastmilk period the infant ingested $11 \mathrm{gm}$. and absorbed $10.35 \mathrm{gm}$. more fat than during either of the cows'-milk periods. In other words, he absorbed 16 per cent. more fat during the breast-milk period than during either of the cows'-milk periods. It may be argued that, if the cows'-milk fat had been raised to 5.4 per cent. for one day, as was the case with the breast-milk, then the absorption of fat in the cows'-milk periods would have equaled that in the breast-milk period. This did not prove true in a patient with infantile atrophy fed on a cows'-milk mixture in which the fat was increased from 2.5 to 3 per cent., the other ingredients and the 
daily quantity remaining unchanged. When the milk contained 2.5 per cent. of fat the dried feces contained 41 per cent.; when the milk-fat was raised to 3 per cent. the dried feces contained 50.5 per cent. of fat. This was a marked increase in the excretion of fat following a relatively slight increase in the fat ingested. Such a high percentage of cows'-milk fat as 5.4 if given to this atrophic infant, who had previously shown his inability to tolerate 3 per cent., would, in my opinion, have terminated the metabolism observation on the first day, owing to the disturbance which it would have caused in the digestion.

The apparent intolerance for cows'-milk fat previously shown by this infant, the fact that so little digestive disturbance followed the administration of an excessive quantity of human milk-fat, and the much larger quantity of fat absorbed during the breast-milk period, may safely be accepted as evidence of a much greater tolerance for human milk fat than for cows'-milk fat. Whether this difference is due to difference in the two kinds of fat or to the presence or absence of other ingredients in the two kinds of milk can be determined only by further experiments.

It is interesting to note that only 4 or 5 per cent. of the fat in the feces is present as neutral fat. I have recently confirmed this observation in a number of normal and atrophic infants. The rennet preparation of cows' milk did not appear to favor the absorption of fat as compared with a similar mixture of cows' milk without rennet.

\section{COMIPARISON OF WEIGHTS}

A comparison of the weights of the infant during the three metabolism periods cannot be made, because the caloric value of the breast-milk and cows'-milk mixtures was not identical. It is interesting, however, to note the gain in weight that was coincident with the administration of breast-milk, which persisted as long as sufficient quantities of breastmilk were given, and that the tolerance for cow's milk became much improved during this time.

The baby was under observation for twenty days previous to admission to the Massachusetts Infants' Asylum. He was $131 / 2$ weeks old and presented the usual symptoms of infantile atrophy. A tuberculin skin test was negative. For the first three days of this period he was given a whey-and-cream mixture which contained 3 per cent. of fat, and for the following nine days a similar mixture which contained 2.5 per cent of fat. The food was then changed to a mixture of cow's milk which contained from 2.75 to 3 per cent. of fat, 6 to 6.5 per cent. of milk-sugar and 1 to 1.5 per cent. of protein. 'The daily quantity' was 840 c.c. There was very little change in the weight during these twenty lays-at the beginning 
$3,460 \mathrm{gm}$. and at the end $3,450 \mathrm{gm}$. The food was not well digested at any time and the baby romited occasionally.

He entered the Massachusetts Infants' Asylum February 18, at the age of $1 \tau$ weeks, and was given a mixture of cows' milk for one day and a malt soup mixture for two days. His condition was so bad at this time that he was given breast-milk. From this date (February 21) to March 10 he was fed on breast-milk and gained in weight from 3,430 to 3,890 gm. in serenteen days; that is, a gain of $460 \mathrm{gm}$. The daily quantity of breast-milk ranged between 840 and $890 \mathrm{gm}$. (28 to $291 / 2$ ounces).

Beginning March 10 he was given daily 840 c.c. of a modification of (ow s milk which contained approximately 3 per cent. of fat, 6 per cent. of milk-sugar and 1 per cent. of protein. This was continued until March 21 . The weight March 10 was $3,890 \mathrm{gm}$., and March 20 it was $3,950 \mathrm{gm}$., a gain of $60 \mathrm{gm}$. in eleven days.

Tomiting occurred on March 21 and for a time the baby was given alternate feedings of breast-milk and a whey-and-cream mixture. March 23 his weight was $3,880 \mathrm{gm}$, and from this date until April 8 (eighteen days) the whey-and-cream mixture and breast-milk were continued in the proportion of one-third to onc-half breast-milk. An uninterrupted gain in weight occurred from $3,880 \mathrm{gm}$. to $4,260 \mathrm{gm} .-380 \mathrm{gm}$.

From April 8 to April 28 a modification of cow's milk containing approximately 3 per cent. of fat, 6 per cent. of milk sugar, and 1 per cent. of protein was substituted for the whey-and-cream-mixture and alter. nated with breast-milk. The baby continued to gain weight from 4,260 $\mathrm{gm}$. to $4,780 \mathrm{gm}-520 \mathrm{gm}$. in twenty days. During the period from March 23 to April 28 the daily quantity of food varied between 925 and 1,000 c.c. April 28 he was $261 / 2$ weeks old and tolerated 3 per cent. of row s-milk fat in from one-hall to two-thirds of the daily quantity of fool ingested. At this time the breast-milk was omitted and he was given 960 c.c. daily of a whey-and-cream mixture. At the end of nine days the modification of cow's milk that previously had been tried was substituted for the whey-and-cream mixture and the baby was put out to board. During these nine days he gained only $80 \mathrm{gm}$. His tolerance for cow:milk had improved so much that he was able to continue to take mixtures of cow's-milk and was sent home in the following September when be was 11 months old, weighing $6,120 \mathrm{gm}$.

I am glad of the opportunity to thank Dr. E. C. Stowell for his great kindness in permitting me to carry out this investigation in the wards of the Massachusetts Infants' Asylum.

In addition $I$ wish to thank the superintendent, Miss Cheney, and her assistant. Miss Mabry, for their supervision of the infant during the observations.

3.) Marlboro Street. 